Thomas-Thi Pluess

Daniel Hayoz

Mette M. Berger

Luc Tappy

Jean-Pierre Revelly

Burkhard Michaeli

Yvon A. Carpentier

René L. Chioléro

\section{Intravenous fish oil blunts the physiological response to endotoxin in healthy subjects}

Published online: 12 June 2007

(C) Springer-Verlag 2007

The online version of the original can be found at http://dx.doi.org/10.1007/s00134-007-0591-5.

T.-T. Pluess · M. M. Berger · J.-P. Revelly · B. Michaeli ·

R. L. Chioléro (ब)

CHUV, Department of Intensive Care Medicine,

1011 Lausanne, Switzerland

e-mail: rene.chiolero@chuv.ch

Tel.: +41-21-3142002

Fax: +41-21-3143045

D. Hayoz

CHUV, Division of Hypertension and Vascular Medicine,

1011 Lausanne, Switzerland

L. Tappy

University of Lausanne, Institute of Human Physiology,

1011 Lausanne, Switzerland

Y. A. Carpentier

Université Libre de Bruxelles, Laboratory of Experimental Surgery,

Brussels, Belgium
Intensive Care Med (2007) 33(5):789-797

\section{Abstract}

Results second sentence should read: Fever was higher in the control group than in FO group. 